\title{
LA PERSPECTIVA DE LA SOSTENIBILIDAD MEDIOAMBIENTAL EN LOS ESTUDIOS DE MÁSTER Y DOCTORADO EN TURISMO EN ESPAÑA
}

\author{
María José Viñals* \\ Universitat Politècnica de València \\ https://orcid.org/0000-0002-7589-7815 \\ Lola Teruel* \\ Universitat Politècnica de València \\ https://orcid.org/0000-0001-6774-4213
}

\section{RESUMEN}

La sostenibilidad ambiental y la formación de los recursos humanos son dos factores estructurales de la competitividad de un destino turístico. El objetivo principal de este trabajo es conocer cómo los estudios superiores de máster y doctorado en España abordan los aspectos de sostenibilidad ambiental. La metodología utilizada para abordar este objetivo ha sido el análisis del contenido de los 55 programas académicos de máster (impartidos por 39 universidades) y los 7 de doctorado (impartidos por 18 universidades) a partir de los documentos publicados en el Registro de Universidades, Centros y Títulos del Ministerio de Ciencia, Innovación y Universidades de España y en las páginas web de las universidades.

Los resultados obtenidos evidencian la baja incidencia que, por el momento, tiene el concepto de sostenibilidad ambiental en los curricula de los másteres, en las líneas de investigación de los programas de doctorado y en las tesis doctorales presentadas en la última década. También se ha observado que su consideración se aborda de forma puntual y aislada en los programas sin insertarse en visiones integrales.

Además de una cuestión de responsabilidad social y económica en relación con el uso de los recursos naturales, se considera que la sostenibilidad ambiental es el área que permite actualmente un mayor margen de mejora de la oferta de los destinos turísticos para incrementar su competitividad. Por tanto, es responsabilidad de las universidades formar a sus estudiantes en el desarrollo de técnicas y competencias que atiendan a estas necesidades del sector e inculcar una ética de los valores ambientales y el respeto por la naturaleza y el planeta.

Palabras clave: Estudios Superiores; España; Máster; Doctorado; Turismo; Sostenibilidad ambiental.

Fecha de recepción: 30 de enero de 2021

Fecha de aceptación: 18 de marzo de 2021

* Centro de Investigación en Arquitectura, Patrimonio y Gestión para el Desarrollo Sostenible (PEGASO). Universitat Politècnica de València (España).E-mail: mvinals@upv.es,dteruel@upvnet.upv.es 


\title{
The perspective of environmental sustainability in master and doctoral tourism stu- dies in Spain
}

\begin{abstract}
Environmental sustainability and human resources education are two structural factors in the competitiveness of a tourist destination. The main objective of the current work is to discover how higher education in master and doctoral studies in Spain address aspects of environmental sustainability. The methodology used to attain the objective was the content analysis of 55 academic master's programmes (taught by 39 universities) and 7 doctoral programmes (taught by 18 universities) based on the documents published in the Legal Register of Universities, Colleges and University Qualifications (Spanish Ministry of Science, Innovation and Universities) and on the websites of the universities.

The obtained results demonstrate that, for the moment, the concept of environmental sustainability has a low impact on the curricula of master's degrees, research lines of the doctoral programmes and on doctoral dissertations presented over the last decade. It has also been noted that environmental sustainability is addressed without being inserted into comprehensive visions.

Beyond a question of social and economic responsibility in relation to the use of natural resources, environmental sustainability is a key area for improvement in the framework of the tourism offer in many destinations to increase their competitiveness. It is, therefore, the responsibility of universities to educate their students in the development of techniques and skills that meet these needs of the sector and to instil them with an ethic of environmental values and respect for nature and the planet.
\end{abstract}

Keywords: Higher Education; Spain; Master; Doctorate; Tourism; Environmental Sustainability.

\section{INTRODUCCIÓN}

España ha demostrado una tendencia creciente y continuada en la recepción de turistas desde que se tiene registros hasta la actualidad. Son ya seis décadas de tendencia positiva que consolidan al turismo español como un sector competitivo a nivel mundial (Ministerio de Industria, Comercio y Turismo, 2020). Esta trayectoria sólo se ha visto truncada, al igual que la mayoría de los destinos del mundo, en el año 2020, por motivo de la pandemia del coronavirus Covid-19.

Según el informe del World Economic Forum (2019), España en 2019 fue por tercer año consecutivo el país más competitivo turísticamente según el Índice de Competitividad de Viajes y Turismo que esta entidad estima cada año. Los indicadores que se usan para este cálculo en los cuales España obtiene las máximas puntuaciones son sus recursos naturales y culturales y las infraestructuras relacionadas con los servicios turísticos. Sin embargo, en este informe, se apunta también que se puede hacer algo más para mejorar los recursos humanos y el mercado laboral.

Al igual que otros países, las crecientes preocupaciones medioambientales a nivel mundial asociadas a los síntomas de sobreexplotación y degradación de los recursos 
naturales y del cambio climático han influido en el sector turístico que, cada vez, es más consciente de la necesidad de adaptar sus estrategias y modelos a una realidad presente que exige una firme responsabilidad ambiental y, a la vez, ofrecer experiencias de calidad para poder seguir siendo competitivos.

La sostenibilidad ambiental, en el marco del sector turístico, es un tema que lleva en la agenda de las organizaciones internacionales y las instituciones públicas nacionales durante varias décadas y todavía no se ha llegado a una situación aceptable que garantice la conservación y el uso racional de los recursos. Los organismos internacionales, incluidos los que se focalizan en el sector turístico como la Organización Mundial del Turismo, y también el Programa para el Medio Ambiente de Naciones Unidas (UNEP y UNTWO, 2005), desde hace décadas, vienen incidiendo en la necesidad de considerar la sostenibilidad ambiental como parte consustancial de la planificación y gestión de cualquier actividad que se desarrolle en el planeta. En particular, hay que recordar que la incorporación de parámetros de sostenibilidad ambiental en el sector turístico se ha convertido en muchos lugares ya en una obligación, gracias a la incidencia de documentos que empezaron a divulgarse desde finales del siglo XX tales como la Carta Mundial del Turismo Sostenible (1995), el Código Ético Mundial para el Turismo (1999), Decisión de la ONU “Turismo y Desarrollo sostenible" (1999), la Agenda Europea por un Turismo sostenible y competitivo (2007), la Declaración de Madrid (2010), la Carta Europea para el Turismo sostenible y responsable (2012) que apuestan por estos postulados. Esto no quiere decir que actualmente se constate una situación óptima de conservación de los recursos ambientales a nivel general; ya que, si bien algunos aspectos de la planificación y gestión del territorio se encuentran regulados por normativas ambientales en muchos países, falta todavía legislación para gestionar adecuadamente algunos temas y queda además sensibilizar e incidir en el desarrollo de la cultura de respeto ambiental para que, definitivamente, se produzca un cambio en los comportamientos de los usuarios y empresarios turísticos.

La incorporación de la sostenibilidad ambiental en los estudios universitarios constituye un pilar fundamental y necesario en la formación, teniendo en cuenta que esta etapa es el preámbulo de la incorporación de los estudiantes a la vida profesional. En el caso de la formación turística, la consideración de la sostenibilidad ambiental es especialmente relevante dado que el turismo está basado en la utilización de los recursos naturales y culturales, los cuales constituyen el principal atractivo de los destinos y la base para el desarrollo de las actividades turísticas. Enseñar cómo asegurar y procurar la conservación de los recursos en el marco de la enseñanza universitaria es un tema crucial para garantizar no solo la supervivencia económica y competitividad del sector turístico sino también por razones de ética medioambiental y social. Por ello, se considera a las universidades como agentes de promoción de la sostenibilidad en la sociedad y a los estudiantes universitarios de turismo como actores clave de todo este proceso; representan el futuro inmediato del sector, considerando que estamos viviendo en un momento de la historia de la Tierra que se caracteriza por la fuerte impronta que tienen las actividades humanas sobre el planeta y que, además, el clima está cambiando con consecuencias evidentes sobre el territorio y, específicamente sobre el desarrollo de la actividad turística.

En este contexto, y pese a la relevancia de España como potencia turística, hay que mencionar que, en nuestro país, la oferta de estudios universitarios de turismo es relati- 
vamente reciente, ya que en el caso de los grados se remonta a finales de los años '90 del siglo XX y los estudios máster y doctorado aparecen ya en el siglo XXI. En cuanto a la orientación de los estudios, los grados responden a una configuración generalista que permite al alumno orientar en un primer momento su futuro profesional, mientras que los másteres consiguen una formación más especializada centrada en temas muy diversos como pueda ser la gestión de destinos, las empresas turísticas, y las tecnologías, entre otros. En el caso de los doctorados, en número creciente, se observa que los programas son también generalistas y que no son tan numerosas las asignaturas que preparan a los estudiantes para poder tomar decisiones relacionadas con la sostenibilidad ambiental de los destinos turísticos, la racional interacción con el medio ambiente de manera ética y responsable y la calidad de la experiencia turística, armonizando el crecimiento económico, la viabilidad social y la preservación de los recursos.

Por todo ello, la cuestión fundamental que plantea este trabajo es conocer si la formación superior de máster y doctorado en turismo en España considera adecuadamente los aspectos de sostenibilidad ambiental para desarrollar en los estudiantes los conocimientos y competencias necesarios para afrontar profesionalmente el futuro inmediato en el que tiene que desenvolverse el sector para seguir manteniendo su nivel de competitividad.

La estructura que sigue este trabajo arranca con una introducción, a la que sigue un apartado que aborda el concepto de la sostenibilidad ambiental, en general, y en los estudios superiores de máster y doctorado en turismo, en particular. El tercer apartado aborda la metodología utilizada para realizar este trabajo que se ha basado en el análisis de contenido de los 55 planes de estudio de los programas de máster y los 7 programas de doctorado ofrecidos por las universidades españolas. Finalmente, se presenta el análisis de los resultados, estableciendo una categorización de la oferta académica en función de la temática que abordan. El último apartado presenta la discusión y conclusiones de este estudio que informan que la oferta de másteres en España está muy enfocada hacia las cuestiones de planificación y dirección de destinos y empresas turísticas, habiendo una baja incidencia del concepto de sostenibilidad ambiental en los estudios de postgrado.

\section{MARCO CONCEPTUAL: LA SOSTENIBILIDAD AMBIENTAL}

Las ideas básicas que definen el concepto de sostenibilidad ambiental tienen que ver con la interacción responsable del hombre con el medio. Se trata de una definición enmarcada en el paradigma del "desarrollo sostenible" descrito en el Informe Brundtland (ONU, 1987), en el que se postulaba el uso racional de los recursos de manera que las necesidades de la población actual se satisfagan sin comprometer las de las generaciones futuras. Por primera vez, se contrastaba, a nivel mundial, el modelo de desarrollo económico en base a la sostenibilidad ambiental. Hay que mencionar que, más de treinta años después, la sostenibilidad ambiental es todavía un tema vigente aún no resuelto. Por ello, es la base del principal marco mundial actual de cooperación internacional: la Agenda 2030 para el Desarrollo Sostenible y sus Objetivos de Desarrollo Sostenible $(O D S)^{1}$. De hecho, a nivel educativo, la Organización de las Naciones Unidas para la Educación, la Ciencia

\footnotetext{
1 https://www.un.org/sustainabledevelopment/es/objetivos-de-desarrollo-sostenible/ (consulta: diciembre
} 2020) 
y la Cultura (UNESCO, 2016) y la Global University Network for Innovation (GUNi, 2019), durante esta década, están emitiendo directrices para poderlos implementar en los estudios universitarios ya que se estima que debe ser un conocimiento y competencia básica de los universitarios.

En relación con el turismo, la sostenibilidad ambiental se considera un tema crucial, ya que la actividad turística es un fenómeno global que se basa en la utilización del territorio y sus recursos que son, a su vez, su mayor activo empresarial (Otero, 2007). Hay que mencionar que la degradación o sobreexplotación de los recursos merma no solo la riqueza ambiental de un destino sino también la social (Büscher et al., 2017; Fletcher, 2019), y la económica debido a la pérdida o degradación de recursos y, por ende, de la calidad de la oferta turística, lo cual repercute en su competitividad, como hemos mencionado anteriormente. Este ha sido un tema constatado a partir del análisis de numerosos casos de estudio por Pulido-Fernández et al. (2019) que han demostrado cómo la expansión insostenible del turismo conlleva un deterioro de los destinos.

Por otra parte, hay que especificar que la sostenibilidad ambiental no va asociada, como se promocionaba hace décadas, a un tipo de espacio o territorio (espacios naturales, espacios rurales), ni a una modalidad turística (Ecoturismo, Turismo rural, Turismo activo, etc.); se trata más bien del modelo de gestión y la gobernanza que rige toda la oferta de actividades y modalidades de un destino. Es evidente que no todas las actividades que se desarrollan en espacios naturales o rurales son sostenibles y, contrariamente, hay que pensar que, por ejemplo, hay playas donde tiene lugar actividades sostenibles. Tampoco hay que creer que toda la oferta etiquetada con "eco" garantiza la sostenibilidad; ciertas campañas de marketing han abusado de este distintivo y se ha generado mensajes poco claros que encubren realidades diferentes a las esperadas, que además contribuyen a la confusión del consumidor.

Hay que destacar que, en la literatura científica, se encuentra una buena aproximación a las cuestiones de sostenibilidad ambiental ya que es un tema al que muchos investigadores han dedicado su atención. Así, la sostenibilidad ambiental ha sido abordada en los estudios universitarios desde diversas disciplinas como la geografía, la ecología o la economía (Ellis y Haff, 2009; Brown et al., 2013; Previdi et al., 2013; Lambrechts et al., 2013; Corlett, 2015), que han estudiado los impactos antrópicos en la atmósfera, geología, geomorfología, hidrología, y en los ecosistemas y procesos geomórficos en general. En relación con los impactos inducidos provocados por la puesta en marcha de actividades turísticas en el territorio hay también numerosas aportaciones (Doxey, 1975; Inskeep, 1991; Boissevain, 1996). Otros autores como Abrahamson (1998), González (2013) y Boyle et al. (2015), han insistido en estas cuestiones, reflexionando en torno a la preocupación por la gestión eficiente de los recursos y también asociándolo a cuestiones emergentes vinculadas con el cambio climático (Hall, 2015). Asimismo, el concepto de la sostenibilidad ambiental también se estudia en relación a las empresas turísticas, concretamente desde la operatividad de las agencias de viajes y las empresas de servicios turísticos (Kilipirisa y Zardava, 2012). Más recientemente, ciertos autores asocian este concepto con el estudio del Antropoceno (Gren y Huijbens, 2016) y también con la posibilidad del decrecimiento turístico como modelo de desarrollo (Blázquez et al., 2019; Higgins-Desbiolles et al., 2019).

Hay que mencionar que la importancia de este tema y su relación con los estudios universitarios ha dado lugar incluso a la aparición de revistas científicas especializadas 
en el tema como International Journal of Sustainability in Higher Education (ISSN 14676370) o International Journal of Higher Education and Sustainability (ISSN 2056-4031).

\section{EL ENFOQUE DE LOS ESTUDIOS DE MASTER Y DOCTORADO EN TURISMO CON RESPECTO A LA SOSTENIBILIDAD AMBIENTAL}

Los programas de posgrado en turismo (másteres oficiales y programas de doctorado) son una excelente forma de mejorar la formación profesional en el sector turístico, alcanzando, de este modo, altos niveles de especialización y también como medio para que los estudiantes se orienten hacia la investigación turística.

En los estudios superiores de turismo, la sostenibilidad ambiental ha sido un tema tratado desde siempre y que numerosos autores han seguido durante este siglo (Butler, 1999; Flohr, 2001; Hardy et al., 2002; Busby, 2003; Saarinen, 2006; Boley, 2011; Barber et al., 2013). De cualquier manera, hay que señalar que los programas universitarios de turismo, en general, presentan mayoritariamente una orientación economicista (Wilson y von der Heidt, 2013), liderada desde las disciplinas de la economía y ciencias empresariales; la sostenibilidad ambiental esta todavía escasamente integrada como tal, en los programas como ya apuntaba Deale et al. (2009) hace más de una década.

Si bien los aspectos económicos resultan relevantes en los estudios de turismo, recientemente, el preocupante escenario planteado a nivel planetario está forzando a las universidades a preocuparse no solo sobre cómo orientar y resolver los problemas ambientales y territoriales sino, sobre todo, a identificar nuevas oportunidades para el sector turístico, redirigiendo e incorporando nuevas ideas, metodologías y prácticas innovadoras en los programas de estudio. Todo ello para preparar a los futuros profesionales en las tomas de decisiones relacionadas con la sostenibilidad ambiental de los destinos turísticos, la racional interacción con el medio ambiente de manera ética y responsable y la calidad de la experiencia turística, a la vez que se mantiene un crecimiento económico, la viabilidad social y la preservación de los recursos.

La forma tradicional de abordar el aprendizaje de la sostenibilidad ambiental ha sido la de adquirir conocimientos teórico-prácticos impartidos desde diferentes disciplinas (Goodwin, 2011). No obstante, autores como Shephard (2007) o Canziani et al. (2012) se plantearon la necesidad de revisar críticamente los modelos educativos y dejar de ser simplemente contenedores de conocimiento para pasar a la acción mediante un aprendizaje significativo. También, el Espacio Europeo de Educación Superior ha facilitado orientaciones hacia nuevas vías sobre cómo se puede adquirir los conceptos de sostenibilidad ambiental (Majó, 2010) y se observa que se lleva a cabo esfuerzos en la introducción de la sostenibilidad en los curricula de la educación superior (Ull et al., 2010). Por ello, en la literatura especializada, aparece la implantación del concepto de la Educación para la Sostenibilidad que se considera como un elemento clave para el cambio (Johnston, 2013; Moscardo y Benkendorff, 2015; Higgins-Desbiolles, 2018). Este tema ha tenido un importante desarrollo entre académicos australianos; así, se comprueba en el trabajo de Christie et al. (2013) y Wilson y von der Heidt (2013) que han estudiado la aplicación de este concepto en sus universidades, concluyendo en la baja implementación de métodos docentes aplicados al desarrollo del aprendizaje de la sostenibilidad. 
Otro enfoque surgido recientemente es el de Aprendiendo con la Naturaleza (Knowing with Nature) impulsado, sobre todo, por autores nórdicos, como puede observarse en el trabajo de Höckert et al. (2020). Esta perspectiva considera como opción de aprendizaje aquella que incorpora aspectos experienciales derivados de actividades que el estudiante realiza al aire libre. De este modo, esta aproximación se desarrolla bien a partir de las salidas de campo y aquellas actividades en donde se cambia de escenario para facilitar el conocimiento con la naturaleza (Taylor, 2017).

También asociado al tema de la sostenibilidad ambiental, se plantea el de la Responsabilidad ambiental, que se basa en actitudes y comportamientos éticos con relación al medio ambiente (Chettiparamb y Kokkranikal, 2012; Leslie, 2012; Mihalic, 2016). Teruel y Viñals (2020) plantean que este aspecto puede desarrollarse a partir de la adquisición de habilidades y destrezas consideradas en las competencias transversales definidas en los programas docentes.

De cualquier manera, queda muchos aspectos que analizar y mejorar en las enseñanzas universitarias de turismo relacionadas con la sostenibilidad ambiental para identificar la mejor forma de integrarlos de formar transversal y coherente en sus curricula, ya que como apuntaba Eber (2003), esta es la única forma de aprendizaje significativo. Otros aspectos relacionados con la metodología docente (¿cómo se enseña?) todavía no se conocen con precisión, están en estos momentos siendo analizados por los académicos, considerándolo como un tema prioritario en turismo (Cotterell et al., 2017; 2019).

\section{METODOLOGÍA}

El objeto de estudio de este artículo ha sido los 55 másteres oficiales universitarios (incluidos 2 másteres Erasmus mundus y las propuestas conjuntas de varias universidades) y los 7 programas de doctorado en turismo que se imparten en 18 universidades españolas. La identificación de los másteres existentes se llevó a cabo mediante consultas en el Registro de Universidades, Centros y Títulos del Ministerio de Ciencia, Innovación y Universidades de España ${ }^{2}$ a partir del uso de las palabras clave "turismo", "turística", "turístico", "turísticas", "turísticos". Adicionalmente, se utilizó el término "hotelera" para abordar una oferta amplia de estudios de máster asociados con este sector productivo.

Una vez identificados, se procedió a clasificarlos en función de la temática principal que abordan, obteniendo una clasificación de 6 grandes grupos:

1. Dirección, planificación y gestión de destinos turísticos

2. Dirección de empresas turísticas

3. Dirección y gestión de empresas hoteleras

4. Turismo cultural y urbano

5. Turismo sostenible

6. Otros. Este grupo incluye másteres focalizados en determinados aspectos del turismo (eventos y congresos, turismo enológico, ocio y deporte, etc.) y también aquellos centrados en la innovación en la gestión.

2 https://www.educacion.gob.es/ruct/consultaestudios.action?actual=estudios (consulta: enero 2021) 
Adicionalmente, se ha añadido un grupo que incluye los programas Erasmus mundus.

Seguidamente, la recopilación de información continuó con la consulta a los sitios web de las universidades españolas que ofrecen estos estudios de máster y doctorado en turismo para obtener los detalles de cada una.

Los contenidos generales analizados han sido el diseño curricular y la organización académica (fecha de comienzo de impartición de los estudios, distribución de créditos por materias y asignaturas, duración de los estudios, modalidad en la que se imparten - presencial, semipresencial u online - , existencia de itinerarios formativos, e idioma en el que se imparten).

Posteriormente, se procedió a analizar el contenido de los programas para conocer el alcance que tiene la consideración de la sostenibilidad ambiental. El análisis se ha centrado, fundamentalmente, en los másteres del Grupo 5 "Turismo sostenible", de los que se ha realizado un análisis cualitativo de las asignaturas que incluyen.

\section{RESULTADOS}

Los resultados obtenidos de este análisis arrojan información sobre las características de los estudios superiores de turismo de máster y doctorado en España, con especial hincapié en la consideración de los aspectos de la sostenibilidad ambiental.

En primer lugar, es importante destacar que los estudios superiores de máster y doctorado de turismo en España son relativamente recientes ya que se incorporan a la universidad en la primera década del siglo XXI; no obstante, desde entonces, ha habido un crecimiento rápido en el número de universidades que han incorporado estos estudios en sus respectivas ofertas. La orientación de estos estudios ha combinado la vertiente profesional con la investigadora, sustentando así esta última los programas de doctorado en turismo. Con relación a la sostenibilidad ambiental, como se verá en detalle más adelante, la oferta existente de programas de máster no presenta una clara conceptualización sobre este tema; lo que se incluye son asignaturas relacionadas con el medio natural y rural y el estudio de los impactos que provocan las actividades turísticas sobre los recursos naturales y el territorio. Por su parte, la oferta de doctorado es, en general, poco especializada, excepto unas pocas universidades que incorporan líneas de investigación más concretas.

A continuación, en primer lugar, se presenta un subapartado con los resultados generales obtenidos del análisis del diseño curricular de los estudios de postgrado de turismo. El segundo subapartado aborda específicamente el tratamiento de los aspectos de la sostenibilidad ambiental.

\subsection{Aspectos generales del diseño curricular de los estudios superiores de máster y doctorado}

La legislación española desarrolla los másteres oficiales en el Real Decreto 56/2005 de 21 de enero, por el que se regulan los estudios universitarios oficiales de Posgrado (Ministerio de Educación y Ciencia, 2005) que distingue entre: estudios de segundo ciclo (máster oficial) y de tercer ciclo (doctorado). Habitualmente, los másteres oficiales se componen de uno o dos cursos académicos. 
La oferta de másteres en turismo para el curso 2020-2021 se concentra en los 55 programas diferentes de 39 universidades públicas y privadas incluidos los dos Erasmus mundus y un programa conjunto compartido por 4 universidades. La figura 1 recoge esta oferta según los seis bloques definidos anteriormente en la metodología.

En relación con los aspectos generales del diseño curricular, hay que señalar que el número de créditos ECTS (European Credit Transfer and Accumulation System)3 , que el alumno debe cursar para finalizar estos estudios es de 60, en la mayoría de los casos, divididos en asignaturas obligatorias, optativas, el Trabajo Final de Máster (TFM), y las prácticas profesionales (opcionales). Del análisis realizado, se desprende que todas las universidades coinciden en ofrecer este número máximo de créditos distribuidos en 1 año a excepción de la universidad Oberta de Catalunya que permite al alumno elegir la opción de matrícula parcial y poder cursarlo en 2 años. El número de créditos dedicados a las materias obligatorias es el más elevado, situándose en 38 como media. Las asignaturas optativas, generalmente enmarcadas en las especializaciones, constituyen un $15 \%$ aproximadamente del total. Por otro lado, los créditos del TFM se sitúan en un intervalo más amplio que va desde los 18 créditos, como aparece en el Máster Universitario en Cultura del Vino: Enoturismo en la Cuenca del Duero de la Universidad de Burgos, hasta los programas que otorgan un número menor, aunque nunca inferior a 6 ECTS. Por otro lado, las prácticas profesionales también denominadas "prácticas externas" aparecen en la mayoría de las ofertas analizadas; el número medio de créditos se sitúa en torno a 6,25 ECTS. En cuanto a la lengua de impartición, hay que decir que para la mayoría de los másteres es el español, observándose una tendencia a incorporar asignaturas en inglés. Por supuesto, en el caso de los programas Erasmus mundus la lengua vehicular es el inglés. La mayoría de las clases son presenciales, pero desde el curso 2020-2021 se ha extendido el modelo semipresencial.

\section{Figura 1 \\ ESTUDIOS UNIVERSITARIOS DE MÁSTER EN TURISMO EN ESPAÑA}

\begin{tabular}{|c|c|c|}
\hline Bloque & Estudios de Máster en Turismo & Nombre de la Universidad \\
\hline \multirow{4}{*}{$\begin{array}{c}1 \\
\text { Dirección, } \\
\text { Planificación } \\
\text { y Gestión } \\
\text { de Destinos } \\
\text { Turísticos }\end{array}$} & Dirección y Planificación de Turismo & $\begin{array}{l}\text { Alicante, Girona, La Laguna, } \\
\text { Málaga, Oviedo, Sevilla, València } \\
\text { (Estudi General), Zaragoza }\end{array}$ \\
\hline & $\begin{array}{l}\text { Planificación y Gestión de Destinos } \\
\text { Turísticos }\end{array}$ & Complutense de Madrid \\
\hline & $\begin{array}{l}\text { Planificación y Gestión de Destinos y } \\
\text { Productos Turísticos }\end{array}$ & A Coruña \\
\hline & Gestión de Destinos Turísticos & Rovira i Virgili \\
\hline
\end{tabular}

3 En español: Sistema Europeo de Transferencia y Acumulación de Créditos. Es el sistema utilizado por las universidades europeas para convalidar asignaturas, dentro del denominado proceso de Bolonia. 


\begin{tabular}{|c|c|c|}
\hline Bloque & Estudios de Máster en Turismo & Nombre de la Universidad \\
\hline \multirow{5}{*}{$\begin{array}{c}2 \\
\text { Dirección } \\
\text { de Empresas } \\
\text { Turísticas }\end{array}$} & Dirección de Empresas Turísticas & $\begin{array}{l}\text { Barcelona (CETT), Castilla La } \\
\text { Mancha, Huelva }\end{array}$ \\
\hline & $\begin{array}{l}\text { Gestión y Dirección de Empresas e } \\
\text { Instituciones Turísticas }\end{array}$ & Politécnica de Cartagena \\
\hline & Empresas y Destinos Turísticos & Antonio de Nebrija \\
\hline & Dirección Turística & Cádiz, Extremadura \\
\hline & $\begin{array}{l}\text { Dirección y Gestión Internacional del } \\
\text { Turismo }\end{array}$ & Lleida, Rey Juan Carlos \\
\hline \multirow{3}{*}{$\begin{array}{c}3 \\
\text { Dirección y } \\
\text { Gestión de } \\
\text { Empresas } \\
\text { Hoteleras* }\end{array}$} & $\begin{array}{l}\text { Dirección y Gestión de empresas } \\
\text { hoteleras }\end{array}$ & $\begin{array}{l}\text { Autónoma de Barcelona, } \\
\text { Complutense de Madrid, Distancia } \\
\text { de Madrid }\end{array}$ \\
\hline & Dirección y Gestión hotelera & $\begin{array}{l}\text { Cantabria, Europea de Canarias, } \\
\text { Murcia }\end{array}$ \\
\hline & Dirección Hotelera y de Restauración & $\begin{array}{l}\text { Barcelona (CETT), Católica San } \\
\text { Antonio, Ramón Llull (ESADE), } \\
\text { Rey Juan Carlos }\end{array}$ \\
\hline \multirow{4}{*}{$\begin{array}{c}4 \\
\text { Turismo } \\
\text { Cultural y } \\
\text { Urbano }\end{array}$} & Turismo cultural & Alicante, Girona \\
\hline & Gestión turística del Patrimonio cultural & Autónoma de Barcelona \\
\hline & Turismo urbano & Barcelona \\
\hline & $\begin{array}{l}\text { Turismo Urbano y Gestión de Empresas } \\
\text { Turísticas }\end{array}$ & Santiago de Compostela \\
\hline \multirow{6}{*}{$\begin{array}{c}5 \\
\text { Turismo } \\
\text { Sostenible }\end{array}$} & $\begin{array}{l}\text { Gestión del Turismo Ecológico y } \\
\text { Sostenible }\end{array}$ & Politécnica de Madrid \\
\hline & Turismo Sostenible y TIC & Oberta de Catalunya \\
\hline & $\begin{array}{l}\text { Planificación y Gestión Sostenible del } \\
\text { Turismo }\end{array}$ & Jaén \\
\hline & $\begin{array}{l}\text { Gestión Turística Sostenible de Recursos } \\
\text { y Destinos }\end{array}$ & Lleida \\
\hline & $\begin{array}{l}\text { Economía del Turismo, del Transporte y } \\
\text { del Medio Ambiente }\end{array}$ & Las Palmas de Gran Canaria \\
\hline & $\begin{array}{l}\text { Gestión Turística Recursos Culturales y } \\
\text { Naturales }\end{array}$ & Carlos III de Madrid \\
\hline \multirow{5}{*}{$\begin{array}{c}6 \\
\text { Otros }\end{array}$} & $\begin{array}{l}\text { Organización de Eventos y Turismo de } \\
\text { Negocios }\end{array}$ & Rey Juan Carlos \\
\hline & $\begin{array}{l}\text { Dirección y Organización de Turismo de } \\
\text { Eventos }\end{array}$ & Autónoma de Barcelona \\
\hline & $\begin{array}{l}\text { Dirección de Proyectos de Ocio, Cultura, } \\
\text { Turismo, Deporte y Recreación }\end{array}$ & Deusto \\
\hline & $\begin{array}{l}\text { Cultura del vino: Enoturismo en la } \\
\text { Cuenca del Duero }\end{array}$ & Burgos \\
\hline & $\begin{array}{l}\text { Dirección y Planificación del Turismo } \\
\text { Interior y de Salud }\end{array}$ & Vigo \\
\hline
\end{tabular}




\begin{tabular}{|c|c|c|}
\hline Bloque & Estudios de Máster en Turismo & Nombre de la Universidad \\
\hline \multirow{7}{*}{$\begin{array}{c}6 \\
\text { Otros }\end{array}$} & $\begin{array}{l}\text { Turismo Electrónico: Tecnologías } \\
\text { Aplicadas a la Gestión y } \\
\text { Comercialización del Turismo }\end{array}$ & Málaga \\
\hline & $\begin{array}{l}\text { Economía del Turismo: Monitorización y } \\
\text { Evaluación }\end{array}$ & Illes Balears \\
\hline & $\begin{array}{l}\text { Dirección de Marketing (empresas } \\
\text { turísticas) }\end{array}$ & Cantabria \\
\hline & Innovación en la Gestión turística & Barcelona (CETT) \\
\hline & $\begin{array}{l}\text { Innovación en Diseño para el Sector } \\
\text { Turístico }\end{array}$ & $\begin{array}{l}\text { Conjuntamente: Barcelona, La } \\
\text { Laguna, Las Palmas de Gran } \\
\text { Canaria, País Vasco }\end{array}$ \\
\hline & Innovación y Marketing Turístico & Católica San Antonio \\
\hline & $\begin{array}{l}\text { Agroecología, Desarrollo Rural y } \\
\text { Agroturismo }\end{array}$ & Miguel Hernández \\
\hline \multirow[b]{2}{*}{$\begin{array}{l}\text { Erasmus } \\
\text { Mundus }\end{array}$} & Innovación en Enoturismo & $\begin{array}{l}\text { Rovira i Virgili; Universidade de } \\
\text { Porto (Portugal) y Université de } \\
\text { Bordeaux (Francia) }\end{array}$ \\
\hline & Gestión del Turismo & $\begin{array}{l}\text { Girona, SyddanskUniversitet } \\
\text { (Denmark) y Univerzi v } \\
\text { Ljubljani-University of Ljubljana } \\
\text { (Eslovenia) }\end{array}$ \\
\hline
\end{tabular}

*La oferta de másteres en hotelería y restauración se ha compendiado en 3 grandes subgrupos si bien la denominación de los programas adquiere hasta 8 denominaciones similares.

(Fuente: Ministerio de Ciencia, Innovación y Universidades) ${ }^{4}$

Como se puede observar en la figura 1, el Grupo 1 se corresponde con másteres dedicados a los aspectos relacionados con la dirección y planificación del turismo e incluye la oferta de11 universidades bajo denominaciones muy similares. Los bloques dedicados a la dirección de empresas turísticas (Grupo 2), en general, y a las empresas hoteleras en particular (Grupo 3), incluyen, entre ambas, la oferta de 19 universidades. Los aspectos vinculados con el turismo cultural y urbano (Grupo 4) recogen temas específicos de adecuación y puesta en valor del patrimonio vinculado a las ciudades (turismo urbano). La oferta especializada de este tipo de estudios no es muy amplia (5 universidades), aunque sí variada. El Grupo 6 incluye una serie de másteres variados ofrecidos por 15 universidades que tratan aspectos muy diversos como el turismo de eventos y congresos, el ocio y el deporte, así como algunas propuestas vinculadas al territorio como es el caso del Máster en Enoturismo de la Universidad de Burgos centrado en el destino "Ribera del Duero".

Un aspecto destacado y transversal a todos los másteres es la incorporación de contenidos vinculados con las tecnologías de la información y las comunicaciones (TIC) en el sector turístico y su aplicabilidad a diferentes sectores. Una oferta que destaca, en

4 https://www.educacion.gob.es/ruct/home (consulta: enero 2021) 
este sentido, es el Máster en Turismo electrónico: Tecnologías Aplicadas a la Gestión y Comercialización del Turismo que ofrece la Universidad de Málaga.

En el Grupo 5, se ha incluido los másteres que tienen una mayor relación con temas vinculados a la sostenibilidad ambiental y que se tratarán con más detalle en los siguientes apartados.

En relación con los programas de doctorado (figura 2), hay que señalar que se ha identificado 18 universidades que los ofrecen. De entre ellas, 14 presentan una oferta denominada Doctorado en Turismo, si bien 12 comparten el mismo programa académico. Por otro lado, aparecen 4 programas más especializados en: Economía Internacional y Turismo; Derecho, Sociedad y Turismo; Turismo, Economía y Gestión; y Turismo y Ocio.

Figura 2

\section{ESTUDIOS UNIVERSITARIOS DE DOCTORADO EN TURISMO EN ESPAÑA}

\begin{tabular}{ll}
\hline Estudios de Doctorado en Turismo & \multicolumn{1}{c}{ Nombre de la Universidad } \\
\hline \multirow{2}{*}{ Turismo } & Antonio de Nebrija, Autónoma de Barcelona, \\
& Complutense de Madrid, Alicante, Cádiz, Girona, \\
& Extremadura, La Laguna, Málaga, Santiago de \\
& Compostela, Sevilla, Vigo, Rey Juan Carlos, Illes Balears, \\
& Oberta de Catalunya \\
\hline Economía Internacional y Turismo & València (Estudi General) \\
\hline Derecho, Sociedad y Turismo & La Laguna \\
\hline Turismo y Ocio & Rovira i Virgili \\
\hline Turismo, Economía y Gestión & Las Palmas de Gran Canaria \\
\hline
\end{tabular}

(Fuente: Ministerio de Ciencia, Innovación y Universidades) ${ }^{5}$

\subsection{La sostenibilidad ambiental en los estudios de postgrado en turismo en España}

La forma en la que los másteres y programas de doctorado en turismo abordan la conceptualización del turismo como fuerza geofísica que es parte de la relación entre el ser humano y el planeta, es muy difusa. Los aspectos de sostenibilidad ambiental, el análisis de los recursos turísticos, el impacto de las actividades turísticas, la sobreexplotación por turismo, etc. están presentes en la literatura científica, como se ha visto, y hay además muchos proyectos de investigación, publicaciones, congresos y estrategias nacionales orientados al estudio de la sostenibilidad para el caso del turismo español (Cebrián, 2003; Pulido-Fernández, 2004; Jiménez Herrero, 2007; Hein et al., 2009; Cañizares, 2013; Torres Delgado, 2013; López-Sánchez y Pulido-Fernández, 2014; Olcina y Vera-Rebollo, 2016; Plumed et al., 2018; Cabello et al., 2021; entre otros), pero este nuevo conocimiento no ha sido incorporado debidamente en los másteres en turismo ni tampoco en los programas de doctorado tal como se puede comprobar al analizar los curricula del Grupo 5 "Turismo sostenible" (figura 3).

\footnotetext{
5 https://www.educacion.gob.es/ruct/home (consulta: enero 2021)
} 


\section{Figura 3 \\ ASIGNATURAS (OBLIGATORIAS Y OPTATIVAS) INCLUIDAS EN LA OFERTA DE MÁSTERES EN TURISMO DEL GRUPO 5 "TURISMO SOSTENIBLE"}

\begin{tabular}{|c|c|c|}
\hline $\begin{array}{l}\text { Máster/ Nombre de } \\
\text { la Universidad }\end{array}$ & Obligatorias & Optativas \\
\hline $\begin{array}{l}\text { Gestión Turística } \\
\text { de Recursos } \\
\text { Culturales } \\
\text { y Naturales } \\
\text { (Universidad } \\
\text { Carlos III de } \\
\text { Madrid) }\end{array}$ & $\begin{array}{l}\text { Gestión de Marca para los recursos y } \\
\text { destinos Turísticos Culturales y Naturales } \\
\text { Emprendiduría y creación de empresas } \\
\text { turísticas } \\
\text { Gestión Turística del Patrimonio Cultural } \\
\text { Legislación sobre Patrimonio Cultural } \\
\text { Políticas y Legislación Medioambiental y } \\
\text { Turística } \\
\text { La Intermediación en el sector turístico } \\
\text { Espacios para la Exhibición y la } \\
\text { Conservación de los Bienes Culturales } \\
\text { Turismo e Industrias Culturales y } \\
\text { Creativas } \\
\text { Cartografía y Sistemas de Información } \\
\text { Geográfica aplicados al Turismo }\end{array}$ & $\begin{array}{l}\text { Centros de Interpretación } \\
\text { Inventario de los Bienes } \\
\text { Naturales: Unidades de } \\
\text { Paisaje } \\
\text { Parques Nacionales y } \\
\text { Otros Espacios Naturales } \\
\text { Protegidos } \\
\text { Rutas Vinculadas al Paisaje } \\
\text { Cultural y la Naturaleza } \\
\text { Planificación, capacidad de } \\
\text { acogida y sostenibilidad }\end{array}$ \\
\hline $\begin{array}{c}\text { Planificación y } \\
\text { Gestión Sostenible } \\
\text { del Turismo } \\
\text { (Universidad de } \\
\text { Jaén) }\end{array}$ & $\begin{array}{l}\text { Turismo sostenible en un mundo } \\
\text { globalizado } \\
\text { Gestión turística, sostenibilidad, y } \\
\text { Responsabilidad Social Corporativa } \\
\text { Técnicas e instrumentos para la } \\
\text { generación de inteligencia turística } \\
\text { Marketing digital y e-commerce }\end{array}$ & $\begin{array}{l}\text { Técnicas y Herramientas de } \\
\text { Planificación Territorial de } \\
\text { Destinos Turísticos } \\
\text { Técnicas y Métodos } \\
\text { Avanzados de Diagnóstico } \\
\text { e Intervención Territorial de } \\
\text { Destinos Turísticos } \\
\text { Técnicas y Herramientas } \\
\text { para la Planificación y } \\
\text { Gestión Económica de } \\
\text { Destinos Turísticos } \\
\text { Gobernanza para la Gestión } \\
\text { de Destinos Turísticos }\end{array}$ \\
\hline $\begin{array}{l}\text { Gestión Turística } \\
\text { Sostenible } \\
\text { de Recursos } \\
\text { y Destinos } \\
\text { (Universitat de } \\
\text { Lleida) }\end{array}$ & $\begin{array}{l}\text { Gobernanza y planificación estratégica de } \\
\text { destinos turísticos sostenibles } \\
\text { Marketing y comercialización de destinos } \\
\text { y productos turísticos sostenibles } \\
\text { Patrimonio, turismo y desarrollo } \\
\text { sostenible } \\
\text { Diseño y gestión sostenible de proyectos } \\
\text { turísticos de desarrollo endógeno }\end{array}$ & $\begin{array}{l}\text { Planificación estratégica del } \\
\text { territorio } \\
\text { Gestión y preservación de los } \\
\text { recursos naturales y espacios } \\
\text { naturales protegidos } \\
\text { Creación e innovación } \\
\text { de productos turísticos } \\
\text { sostenibles basados en los } \\
\text { recursos naturales } \\
\text { Planificación sostenible para } \\
\text { el desarrollo del turismo } \\
\text { natural }\end{array}$ \\
\hline
\end{tabular}




\begin{tabular}{|c|c|c|}
\hline $\begin{array}{l}\text { Máster/ Nombre de } \\
\text { la Universidad }\end{array}$ & Obligatorias & Optativas \\
\hline $\begin{array}{l}\text { Turismo Sostenible } \\
\text { y TIC (Universitat } \\
\text { Oberta de Catalunya) }\end{array}$ & $\begin{array}{l}\text { Sostenibilidad y turismo } \\
\text { Sistemas de información y comunicación } \\
\text { para la sostenibilidad turística } \\
\text { Turismo, cultura y sociedad } \\
\text { Gestión y planificación sostenible de destinos } \\
\text { turísticos } \\
\text { Sostenibilidad y nuevos productos turísticos } \\
\text { Gestión de sistemas de información en } \\
\text { turismo } \\
\text { Emprendimiento, liderazgo y gestión del } \\
\text { cambio } \\
\text { Turismo, movilidades y sostenibilidad } \\
\text { Redes sociales y turismo inteligente } \\
\text { Gobernanza y resiliencia social en destinos } \\
\text { turísticos } \\
\text { Métodos de investigación en turismo }\end{array}$ & $\begin{array}{l}\text { Turismo inclusivo } \\
\text { Turismo creativo, destinos } \\
\text { creativos } \\
\text { Eventos, sociedad y } \\
\text { sostenibilidad } \\
\text { Estrategias de revitalización para } \\
\text { destinos maduros sostenibles }\end{array}$ \\
\hline $\begin{array}{l}\text { Gestión del } \\
\text { Turismo Ecológico } \\
\text { y Sostenible } \\
\text { (Universidad } \\
\text { Politécnica de } \\
\text { Madrid) }\end{array}$ & $\begin{array}{l}\text { Introducción, conceptualización e } \\
\text { importancia del turismo ecológico y } \\
\text { sostenible } \\
\text { Recursos económicos y gestión financiera de } \\
\text { los fondos } \\
\text { Construcción sostenible y eficiencia } \\
\text { energética } \\
\text { Productos de Ecoturismo } \\
\text { Formulación y evaluación de Proyectos de } \\
\text { Turismo } \\
\text { Patrimonio Cultural }\end{array}$ & $\begin{array}{l}\text { Turismo de Observación de } \\
\text { Naturaleza } \\
\text { Turismo en espacios naturales } \\
\text { protegidos } \\
\text { SIG diseño de rutas y } \\
\text { elaboración cartográfica } \\
\text { Emprendimiento e Innovación } \\
\text { en Turismo Sostenible } \\
\text { Responsabilidad Social y } \\
\text { Certificación en Empresas } \\
\text { Sostenibles }\end{array}$ \\
\hline $\begin{array}{c}\text { Economía del } \\
\text { Turismo, del } \\
\text { Transporte y del } \\
\text { Medio Ambiente } \\
\text { (Universidad de } \\
\text { Las Palmas de Gran } \\
\text { Canaria) }\end{array}$ & $\begin{array}{l}\text { Análisis coste-beneficio } \\
\text { Análisis de la calidad de servicio } \\
\text { Análisis del turismo } \\
\text { Análisis y predicción de la demanda } \\
\text { Economía del medio ambiente } \\
\text { Economía del transporte } \\
\text { Métodos cuantitativos } \\
\text { Planificación territorial del turismo y del } \\
\text { transporte }\end{array}$ & \\
\hline
\end{tabular}

(Fuente: páginas web de las universidades en Anexo I)

En este Grupo 5 de másteres, a priori, no se distingue claramente entre los que presentan una orientación profesionalizante y los que conducen hacia la investigación; aunque por los syllabi presentados y la inexistencia de prácticas en empresa se presume, para la mayoría de ellos, un carácter más bien investigador. No obstante, si se asume el carácter investigador de esta línea de másteres, llama la atención en sus curricula la falta de más asignaturas metodológicas y de orientación a la investigación. 
Del análisis de contenidos a partir del listado de asignaturas obligatorias y optativas de los másteres de este bloque 5, que en su denominación hacen mención como palabras clave a la "sostenibilidad", "medio ambiente" o a "recursos naturales", hay que destacar que solamente dos de ellos, el de la Universidad de Jaén (Planificación y gestión sostenible del turismo) y el de la Universitat de Lleida (Gestión turística sostenible de recursos y destinos) presentan ciertas similitudes en su denominación y también resultan los más coherentes en su planteamiento. Ambos inciden sobre aspectos territoriales, recursos naturales y la sostenibilidad como cualidad de la planificación y la gestión. Destaca también el hecho que incluyen asignaturas relativas a la gobernanza de los destinos, hecho este de gran interés si se trata de considerar la sostenibilidad como modelo de gestión. Además, el máster de la Universidad de Jaén incluye asignaturas que desarrollan técnicas y herramientas de planificación y gestión. Por su parte, el máster de la Universitat de Lleida desarrolla también, asociado a la sostenibilidad, el tema de los recursos y espacios naturales protegidos. Hay que comentar que, desde que, en 1994, la Unión Mundial para la Naturaleza (UICN) aprobó el sistema de categorización de áreas protegidas incluyendo la Categoría VI: Área protegida con uso sostenible de los recursos naturales (Dudley, 2008), la sostenibilidad ambiental como concepto quedó ligada indisolublemente en el imaginario de las personas, al menos en teoría, a los espacios naturales. Esta idea trascendió también en el ámbito académico; de manera que, cuando se etiqueta alguna asignatura o curso con la denominación de "espacios naturales" parece ser que implícitamente vaya asociada la sostenibilidad ambiental, aunque la realidad nos ha demostrado que esto no es siempre así. En este sentido, hay que señalar que, entre los másteres analizados de este grupo, el de la Universidad Carlos III (Gestión turística de los recursos culturales y naturales) se centra en este tema y también en el patrimonio cultural, aunque el abordaje de la sostenibilidad solamente aparece tratado en una asignatura optativa.

También relacionado con el concepto de espacios naturales, se puede mencionar el máster de la Universidad Politécnica de Madrid (Turismo ecológico y sostenible), aunque más que en un tipo de escenario, focaliza en una modalidad turística que se basa en la naturaleza. Entre las asignaturas ofertadas, se hace referencia frecuentemente a conceptos como "ecológico", "ecoturismo", "turismo en espacios naturales protegidos", "turismo sostenible" para caracterizar los contenidos.

Se podría decir que estos másteres que focalizan sobre los espacios naturales, en realidad, se basan en la idea de recreación al aire libre. Hay que mencionar que la gestión de la recreación al aire libre es un área con buenas perspectivas de desarrollo profesional para los estudiantes de turismo que debe ser mejor explorada y planteada en los estudios universitarios. En los EE.UU., las actividades de recreación al aire libre desde $2016^{6}$ son computadas en el producto interior bruto del país (Outdoor Industry Association, 2017) y son objeto de títulos universitarios específicos. Hay que recordar que este tema estaba parcialmente abordado también en el máster de la Universidad de Deusto en Dirección de Proyectos de Ocio, Cultura, Turismo, Deporte y Recreación, incluido en el Grupo 6 por su vinculación con los temas de actividades al aire libre.

6 U.S. Outdoor Recreation Jobs and Economic Impact Act (https://sgbonline.com/u-s-senate-approvesoutdoor-rec-act/) (consulta: diciembre 2020) 
Por otra parte, se atisba el abordaje de la sostenibilidad ambiental en relación con las empresas turísticas en algunas asignaturas que tratan del diseño de actividades, la calidad o la responsabilidad social corporativa. En este sentido, destaca la propuesta hecha por las universidades Carlos III de Madrid (en coherencia con su máster), la de Jaén y la Oberta de Catalunya.

Por tanto, se observa que, de los seis másteres existentes en esta temática, cuatro de ellos han vinculado, de una manera u otra, la sostenibilidad ambiental con los espacios naturales. Sin embargo, los otros dos, que etiquetan su oferta con la sostenibilidad, el de la Universitat Oberta de Catalunya (Turismo sostenible y TIC) y el de la Universidad de Las Palmas de Gran Canaria (Economía del Turismo, del Transporte y del Medio Ambiente), apuntan en otra dirección. El primero se centra en la gobernanza, los destinos inteligentes y en las tecnologías, así como en nuevos productos turísticos, mientras que el segundo tiene un enfoque económico, y el concepto de sostenibilidad va asociado a la asignatura de Economía del Medio Ambiente.

En cuanto a los programas de doctorado actuales (figura 4), 18 universidades españolas presentan oferta, y se estructuran a partir de diversas líneas de investigación.

\section{Figura 4}

\section{LÍNEAS DE INVESTIGACIÓN QUE DESARROLLAN LOS PROGRAMAS DE DOCTORADO EN TURISMO OFERTADOS EN LAS UNIVERSIDADES ESPAÑOLAS}

\begin{tabular}{|c|c|c|}
\hline $\begin{array}{l}\text { Denominación } \\
\text { programa de } \\
\text { doctorado }\end{array}$ & Líneas de investigación & Universidad \\
\hline Turismo & $\begin{array}{l}\text { Planificación y gestión de destinos turísticos, } \\
\text { turismo y sociedad local } \\
\text { Análisis económico del sector turístico } \\
\text { Gestión e innovación en organizaciones } \\
\text { turísticas } \\
\text { Turismo y patrimonio } \\
\text { Inteligencia en el ámbito turístico. TICS y } \\
\text { análisis de datos }\end{array}$ & $\begin{array}{l}\text { Alicante, Antonio de } \\
\text { Nebrija, Complutense } \\
\text { de Madrid, Cádiz, } \\
\text { Extremadura, La Laguna, } \\
\text { Málaga, Oberta de } \\
\text { Catalunya, Rey Juan Carlos } \\
\text { I, Santiago de Compostela, } \\
\text { Sevilla, Vigo }\end{array}$ \\
\hline Turismo & $\begin{array}{l}\text { La innovación, gestión y desarrollo de } \\
\text { productos turísticos } \\
\text { La gestión y marketing de destinos turísticos } \\
\text { El comportamiento de los turistas } \\
\text { Los impactos del turismo y sostenibilidad }\end{array}$ & Girona, Illes Balears \\
\hline Turismo & $\begin{array}{l}\text { Turismo, cultura, patrimonio y lengua } \\
\text { Administración y organización de empresas e } \\
\text { instituciones turísticas } \\
\text { Análisis de mercados turísticos y creación e } \\
\text { innovación de productos turísticos } \\
\text { Turismo, territorio, paisaje y medio ambiente }\end{array}$ & Autónoma de Barcelona \\
\hline
\end{tabular}




\begin{tabular}{c|ll}
$\begin{array}{c}\text { Denominación } \\
\text { programa de } \\
\text { doctorado }\end{array}$ & \multicolumn{1}{c|}{ Líneas de investigación } & \multicolumn{1}{c}{ Universidad } \\
\hline $\begin{array}{c}\text { Economía } \\
\text { Internacional y } \\
\text { Turismo }\end{array}$ & $\begin{array}{l}\text { Economía Internacional e Integración } \\
\text { Marketing Internacional y Turismo }\end{array}$ & València (Estudi General) \\
\hline Turismo, & Turismo y Desarrollo Sostenible \\
Economía y & $\begin{array}{l}\text { Economía y Métodos Cuantitativos } \\
\text { Gestión }\end{array}$ & $\begin{array}{l}\text { Lastión } \\
\text { Canaria }\end{array}$ \\
\hline $\begin{array}{c}\text { Derecho, } \\
\text { Sociedad y } \\
\text { Turismo }\end{array}$ & $\begin{array}{l}\text { Ciencias sociales } \\
\text { Economía } \\
\text { Derecho }\end{array}$ & La Laguna \\
\hline Burismo y Ocio & $\begin{array}{l}\text { Branding y comunicación turística } \\
\text { Consumo, ocio y experiencia turística }\end{array}$ \\
\hline & $\begin{array}{l}\text { Desarrollo sostenible e impactos del turismo } \\
\text { Movilidad, destinos y gobernanza del turismo }\end{array}$ \\
\hline
\end{tabular}

(Fuente: páginas web de las universidades en Anexo I)

Los programas de doctorado en turismo en España se iniciaron hace más de una década impulsados por las universidades de Málaga, Illes Balears y Alfonso X el Sabio. A esta oferta, se unieron las universidades de Alicante, Sevilla y Rey Juan Carlos que con la Universidad de Málaga confeccionaron un programa de doctorado conjunto al que, posteriormente, se han ido sumando otras universidades como la de Extremadura, Cádiz, Complutense de Madrid, La Laguna, Santiago de Compostela, Vigo, Antonio de Nebrija y la Oberta de Catalunya. Se trata de un programa genérico que incluye 5 líneas de investigación variadas que abarcan aspectos de planificación y gestión de los destinos, análisis económico, aspectos de gestión en innovación en organizaciones turísticas, turismo y patrimonio, así como aspectos de inteligencia turística, TICs y análisis de datos.

Por otro lado, se identifica la oferta de las universidades de Girona e Illes Balears que cuentan con un programa de doctorado con la misma denominación, pero con líneas de investigación diferentes. Este último está centrado en la innovación, gestión y desarrollo de productos turísticos, la gestión del marketing de destinos, el comportamiento de los turistas y una última línea de investigación que se podría vincular más directamente con la sostenibilidad ambiental denominada "los impactos del turismo y sostenibilidad". El título genérico del programa de doctorado en Turismo de la Universidad Autónoma de Barcelona propone otras líneas de investigación como el estudio de las empresas e instituciones turísticas, el análisis de los mercados turísticos y la creación e innovación en los productos turísticos, además de dos líneas vinculadas con el territorio, el paisaje y el medio ambiente, así como con aspectos culturales, patrimoniales y lingüísticos.

Finalmente, las universidades de València (Estudi General) y de Las Palmas de Gran Canaria se centran en temas económicos; la Universidad de La Laguna se decanta por aspectos legales y sociales del turismo, mientras que la de Rovira i Virgili resulta muy innovadora en el panorama nacional al incorporar los aspectos de ocio y recreación, además de una línea de investigación dedicada al desarrollo sostenible e impactos del turismo. 
Hay que comentar que las universidades que ofertan másteres del Grupo 5 no tienen continuidad con un programa de doctorado, salvo el caso de la Universidad de las Palmas de Gran Canaria. De este modo, resulta sorprendente que exista un grupo de universidades que ofrecen másteres orientados a la investigación que luego no tengan continuidad en programas de doctorado para así poder completar la trayectoria investigadora de los estudiantes. La mayor parte de universidades que ofrece conjuntamente máster y programa de doctorado son las del Grupo 1 (Alicante, Complutense de Madrid, Girona, La Laguna, Málaga, Sevilla, Rovira i Virgili y València) y las de los Grupos 2 y 3 (Antonio Nebrija, Cádiz, Extremadura, Rey Juan Carlos y Autónoma de Barcelona).

Con relación a la defensa de tesis doctorales relacionadas con la sostenibilidad ambiental, la producción científica existente es todavía escasa. Desde que se pusieron en marcha los programas de doctorado ha habido una clara dominancia de las tesis relacionadas con las disciplinas de economía y geografía (Agència Valenciana del Turisme, 2006; Ortega et al., 2013; Torres-Rojas y García-Delgado, 2015; Sepúlveda y Plumed, 2018; Peña Sánchez et al., 2019). La relación estricta de tesis registradas, en los últimos diez años, en la base de datos $\mathrm{TESEO}^{7}$ en cuyo título aparece conjuntamente los conceptos de "turismo", "sostenibilidad ambiental", y "espacios naturales" es de 13 trabajos ${ }^{8}$, considerando que pueden haber sido leídas en programas de doctorado no exclusivamente de turismo. Se trata de un número bajo por el momento, si se compara con el total de 549 tesis que se han presentado en el mismo periodo y en cuyo título aparecía la palabra "turismo", "turística/s" o "turístico/s".

Por tanto, y como reflexión general sobre la consideración de la sostenibilidad ambiental en los programas de doctorado de turismo en España, se puede decir que 12 universidades presentan una oferta genérica que incluye líneas de investigación que abarcan temáticas muy variadas donde se puede enmarcar casi cualquier aspecto relacionado con la investigación turística. Luego, hay 3 universidades más focalizadas en temas económicos y finalmente 4 universidades que se acercan discretamente más a los temas de sostenibilidad ambiental (Rovira i Virgili, Girona, Illes Balears y Autónoma de Barcelona).

\section{DISCUSIÓN Y CONCLUSIONES}

En líneas generales, y como reflexiones finales en relación con las cuestiones iniciales que se planteaban en esta investigación sobre la forma y el alcance de la implantación de la sostenibilidad ambiental en los programas de máster y doctorado en turismo de España, se puede decir que la incidencia es baja. A pesar del número elevado de programas de máster existente, la especialización en temas de sostenibilidad ambiental y la oferta de asignaturas que abordan este tema, así como las líneas de investigación de los programas de doctorado en turismo, es escasa y confusa; no hay una consideración precisa del concepto en los syllabi de los programas. En estos momentos, no existe una oferta temática consolidada que pueda completar la especialización de los estudiantes en temas de sostenibilidad ambiental en la fase de postgrado. Estos temas se abordan de forma aleatoria en algunos programas sin identificarse una oferta coherente.

7 Fichero central de tesis doctorales de las universidades españolas cuya web está gestionada por el Ministerio de Educación, Cultura y Deporte de España.

8 https://www.educacion.gob.es/teseo/listarBusqueda.do (consulta: febrero 2021). 
Hay que comentar que la falta de definición de una oferta concreta con relación al abordaje de este concepto es también la tónica general de los másteres en otros países como se puede deducir de la búsqueda en páginas web de universidades extranjeras que ofrecen másteres en turismo. Así, se observa que en estas universidades se incluye en su denominación el concepto de sostenibilidad, pero también lo hacen de forma muy vaga para cualificar el tipo de turismo ("sustainable tourism", "sustainable tourism management", etc.) y también se aprecia que aparece vinculado especialmente a los espacios naturales o al ecoturismo.

Otra reflexión que se desprende tras analizar la oferta de asignaturas de los másteres españoles es la enorme diversidad temática y la falta de uniformidad en la denominación de las mismas. Cada universidad ha configurado una oferta académica siguiendo sus propios criterios sin coordinarse con otras universidades. De esta forma, aparece planes de estudio que, bajo denominaciones muy similares, ofrecen programas diferentes. Este hecho puede ser considerado como una debilidad del sistema ya que se debería prever unos ciertos contenidos comunes, al igual que ocurre en el grado, para programas que se denominan de forma muy parecida; de manera que un estudiante pueda equiparar sus conocimientos y competencias profesionales en cualquier contexto y circunstancia y también que los empleadores sepan el perfil profesional que subyace tras los títulos de los candidatos. El hecho de que se simplifique, reordene y regule la oferta bajo unas mínimas directrices temáticas agrupadas en bloques con asignaturas comunes sería muy necesario.

Por tanto, se puede decir que hay un margen de mejora muy amplio y que debería iniciarse un proceso de actualización de los planes de estudio (algunos de ellos tienen más de una década de implantación) y aprovechar para una reestructuración de los contenidos de manera que se incluya itinerarios formativos especializados, coherentes y ajustados a la necesidad de incorporar la sostenibilidad ambiental.

Como conclusión final, solamente queda mencionar el hecho de que la situación medioambiental del planeta exige a todos los sectores de la economía replantear sus esquemas productivos hacia enfoques más sostenibles. En el sector turístico, esa mejora pasa irremediablemente por una formación adecuada de los recursos humanos; de manera que, desde cualquier puesto de trabajo en el sector (instituciones públicas, empresas de hostelería, gestores de patrimonio, etc.), se contribuya a una gobernanza racional de los recursos naturales basada en los principios de la sostenibilidad ambiental. Las universidades tienen capacidad y medios para dar respuesta a ese reto; por ello, deben tener la voluntad de adecuar sus programas a las nuevas necesidades sociales y ambientales, de manera que su oferta de una respuesta real a los cambios que hay que afrontar; es su responsabilidad formar, de la mejor manera posible, a sus estudiantes para que sepan acometer los difíciles retos que supone la gestión del disfrute respetuoso de los recursos de este planeta.

\section{BIBLIOGRAFÍA}

ABRAHAMSON, C.E. (1998): "Storytelling as a pedagogical tool in higher education". Education, vol. 118 (3). 440+. Gale Academic.

BARBER, N., DEALE, C. y GOODMAN, R. (2013): "Environmental sustainability in the hospitality management curriculum: Perspectives from three groups of stakeholders". Journal of Hospitality \& Tourism Education, vol. 21 (1), pp. 6-17. 
BLÁZQUEZ, M., BLANCO-ROMERO, A., VERA-REBOLLO, F. e IVARS, J. (2019): "Territorial tourism planning in Spain: From boosterism to tourism degrowth?" Journal of Sustainable Tourism, vol. 27, pp. 1.764-1.785.

BOISSEVAIN, J. (1996): Coping with Tourists: European Reactions to Mass Tourism. Berghahn Books, 264 pp.

BOLEY, B.B. (2011): "Sustainability in hospitality and tourism education: Towards and integrated curriculum”. Journal of Hospitality \& Tourism Education, vol. 23 (4), pp. 22-31.

BOYLE, A., WILSON, E. y DIMMOCK, K. (2015): “Transformative Education and Sustainable Tourism: The Influence of a Lecturer's Worldview". Journal of Teaching in Travel \& Tourism, vol. 15 (3), pp. 252-263.

BROWN, A.G., TOOTH, S., CHIVERRELL, R.C., ROSE, J., THOMAS, D.S.G., WAINWRIGHT, J., BULLARD, J.E., THORNDYCRAFT, V.R., AALTO, R. y DOWNS, P. (2013): “The Anthropocene: Is therea geomorphological case?" Earth Surface Processes and Landforms, vol. 38 (4), pp. 431-434.

BUSBY, G. (2003): "The concept of sustainable tourism within the higher education curriculum: A British case study". Journal of Hospitality, Leisure, Sport and Tourism Education, vol. 2 (2), pp. 48-58.

BÜSCHER, B., FLETCHER, R., BROCKINGTON, D., SANDBROOK, C., ADAMS, W.M., CAMPBELL, L., CORSON, C., DRESSLER, W. DUFFY, R., GRAY, N., HOLMES, G., KELLYN, A., LUNSTUM, E., RAMUTSINDELA, M. y SHANKER, K. (2017): "Half-Earth or Whole Earth? Radical ideas for conservation and their implications". Oryx, vol. 51 (3), pp. 407-410.

BUTLER, R.W. (1999): "Sustainable tourism: A state-of-the-art review". Tourism Geographies, vol. 1 (1), pp. 7-25.

CABELLO, J.M., NAVARRO-JURADO, E., THIEL-ELLUL, D., RODRÍGUEZ-DÍAZ, B. y RUIZ, F. (2021): “Assessing environmental sustainability by the double reference point methodology: the case of the provinces of Andalusia (Spain)". International Journal of Sustainable Development \& World Ecology, vol. 28 (1), pp. 4-17.

CANZIANI, B.F., SÖNMEZ, S., HSIEH, Y. y BYRD, E.T. (2012): “A Learning Theory Framework for Sustainability Education in Tourism". Journal of Teaching in Travel and Tourism, vol. 12 (1), pp. 3-20.

CAÑIZARES, M.C. (2013): "Sostenibilidad y Turismo: de la documentación internacional a la planificación en España «Horizonte 2020»". Boletín de la Asociación de Geógrafos Españoles, ${ }^{\circ}$ 61, pp. 67-92.

CEBRIÁN, A. (2003): "Sostenibilidad ambiental y Turismo de traspaís en España". Nimbus, $\mathrm{n}^{\mathrm{o}} 11-12$, pp. 47-66.

CHETTIPARAMB, A. y KOKKRANIKAL, J. (2012): "Responsible Tourism and Sustainability: The Case of Kumarakom in Kerala, India". Journal of Policy Research in Tourism, Leisure and Events, vol. 4 (3), pp. 302-326.

CHRISTIE, B.A., MILLER, K.K., COOKE, R. y WHITE, J.G. (2013) “Environmental sustainability in higher education: how do academics teach?" Journal of Environmental Education Research, vol. 19 (3), pp. 655-686. 
COMISIÓN DE LAS COMUNIDADES EUROPEAS (2007): Agenda para un turismo europeo sostenible y competitivo. https://eur-lex.europa.eu/legal-content/ES/TXT/PDF /?uri=CELEX:52007DC0621\&from=ES

CONFERENCIA MUNDIAL DEL TURISMO SOSTENIBLE (1995): Carta del Turismo sostenible. Lanzarote, Islas Canarias, España, del 27 al 28 de Abril de 1995. http://www. datosdelanzarote.com/Uploads/doc/20051226123220895CartaTurismoLanzarote.pdf

CORLETT, R.T. (2015): “The Anthropocene concept in ecology and conservation”. Trends in Ecology \& Evolution, vol. 30 (1), pp. 36-41.

COTTERELL, D., BENCKENDORFF, P. y ZEHRER A. (2017): “Teaching for strong sustainability in university tourism courses". En: Benckendorff \& Zehrer A. (Eds.): Handbook of teaching and learning in tourism. Edwards Elgar Publishing; Cheltenham, pp. 373-388.

COTTERELL, D., HALES, R., ARCODIA, C. y FERREIRA, J.A. (2019): “Overcommitted to tourism and under committed to sustainability: The urgency of teaching strong sustainability in tourism courses". Journal of Sustainable Tourism, vol. 27 (7), pp. 882-902.

DEALE, C., NICHOLS, J. y JACQUES, P. (2009): “A Descriptive Study of Sustainability Education in the Hospitality Curriculum". Journal of Hospitality and Tourism Education, vol. 21 (4), pp. 34-42.

DOXEY, G. (1975): “A causation theory of visitor-resident irritants, methodology and research inferences”. En The impact of tourism. Sixth Annual. Conference of the Travel Research Association. San Diego, USA, pp. 195-198.

DUDLEY, N. (Ed.) (2008): Directrices para la aplicación de las categorías de gestión de áreas protegidas. Gland, Suiza: UICN, 96pp.

ELLIS, E.C. y HAFF, P. (2009): "Earth Science in the Anthropocene: New Epoch", New Paradigm, New Responsibilities. Eos Transactions American Geophysical Union, 90.

EUROPEAN COMMISSION (2012): Charter for Sustainable and Responsible Tourism. Enterprise and Industry. EU Directorate General. http://www.redeuroparc.org/actividades/carta-europea-turismo-sostenible

GREN, M. y HUIJBENS, E.H. (2016): Tourism and the Anthropocene. Routledge.

FLETCHER, R. (2019): "Ecotourism after nature: Anthropocene tourism as a new capitalist "fix". Journal of Sustainable Tourism, vol. 27 (4), pp. 522-535.

FLOHR, S. (2001): “An Analysis of British Postgraduate Courses in Tourism: What Role does Sustainability Play within Higher Education? "Journal of Sustainable Tourism, vol. 9 (6), pp. 505-513.

GOODWIN, H. (2011): Taking Responsibility for Tourism. Goodfellow Publishers Limited.

GONZÁLEZ, J.A.M. (2013): “La sostenibilidad en el sector turístico: del marco ambiental global al marco económico-social local”. Desarrollo Local Sostenible, vol. 6 (17).

GUNI (2019): Implementing the 2030 Agenda at Higher Education Institutions: Challenges and Responses. Ed. Global University Network for Innovation. http://www. guninetwork.org/files/guni_publication_implementing_the_2030_agenda_at_higher_ education_institutions_challenges_and_responses.pdf 
HALL, C.M. (2015): "Changing Paradigms and Global Change: From Sustainable to Steady-state Tourism”. Tourism Recreation Research, vol. 35 (2), pp. 131-143.

HARDY, A., BEETON, R.J.S. y PEARSON, L. (2002): "Sustainable tourism: An overview of the concept and its position in relation to conceptualisations of tourism". Journal of Sustainable Tourism, vol. 10 (6), pp. 475-496.

HEIN, L., METZGER, M.J. y MORENO, A. (2009): "Potential impacts of climate change on tourism; a case study for Spain". Current Opinion in Environmental Sustainability, vol. 1 (2), pp. 170-178.

HIGGINS-DESBIOLLES, F. (2018): "Sustainable tourism: Sustaining tourism or something more?" Tourism Management Perspectives, vol. 25, pp. 157-160.

HIGGINS-DESBIOLLES, F., CARNICELLI, S., KROLIKOWSKI, C., WIJESINGHE, G. y BOLUK, K. (2019): “Degrowing tourism: Rethinking tourism”. Journal of Sustainable Tourism, vol. 27 (12), pp. 1.926-1.944.

INSKEEP, E. (1991): Tourism Planning: An integrated and Sustainable Development Approach. VanNostrandReinold.

JIMÉNEZ HERRERO, L.M. (2007): Hacia la sostenibilidad turística en España. Estudios Turísticos, $\mathrm{n}^{\circ}$ 172-173, pp. 73-79.

JOHNSTON, L.F. (Ed.). (2013): Higher Education for Sustainability. Cases, Challenges, and Opportunities from Across the Curriculum. Ed. Routledge, Taylor \& Francis Group, New York and London.

KILIPIRISA, F. y ZARDAVA, S. (2012): "Developing sustainable tourism in a changing environment: Issues for the tourism enterprises (travel agencies and hospitality enterprises)". Procedia - Social and Behavioral Sciences, vol. 44, pp. 44-52.

LAMBRECHTS, W., MULÀ, I., CEULEMANS, K., MOLDEREZ, I. y GAEREMYNCK, V. (2013): "The integration of competences for sustainable development in higher education: An analysis of bachelor programs in management". Journal of Cleaner Production, vol. 48, pp. 65-73.

LESLIE, D. (2012): Responsible Tourism. Concepts, Theory and Practice. Wallingford.

LÓPEZ-SÁNCHEZ, Y. y PULIDO-FERNÁNDEZ, J.I. (2014): “Incorporating sustainability into Tourism policy: A strategic agenda for Spain”. European Journal for Tourism Research, vol. 7, pp. 57-78.

MAJÓ, J. (2010): "Las propuestas de Grado en Turismo en el Espacio Europeo de Educación Superior (EEES)". EstudiosTurísticos, n 184, pp. 137-181.

MIHALIC, T. (2016): "Sustainable-responsible tourism discourse - Towards 'responsustable' tourism". Journal of Cleaner Production, vol. 111, pp. 461-470.

MINISTERIO DE EDUCACIÓN Y CIENCIA DE ESPAÑA (2005): Real Decreto Real Decreto 56/2005 de 21 de enero, por el que se regulan los estudios universitarios oficiales de Posgrado. Boletín Oficial del Estado, 303, de 20 de diciembre de 2005. Referencia: BOE-A-2005-20881.

MINISTERIO DE CIENCIA, INNOVACIÓN Y UNIVERSIDADES (n.d.): Registro oficial de Títulos universitarios. https://www.educacion.gob.es/ruct/home

MINISTERIO DE INDUSTRIA COMERCIO Y TURISMO (2020): Directrices generales de la Estrategia de Turismo Sostenible de España 2030. https://turismo.gob.es/es-es/ estrategia-turismo-sostenible/Documents/directrices-estrategia-turismo-sostenible.pdf 
MOSCARDO, G. y BENKENDORFF, P. (Eds.) (2015): Education for Sustainability in Tourism. A Handbook of Processes, Resources, and Strategies. Ed. Springer-Verlag, Berlín Heidelberg.

OLCINA, J. y VERA-REBOLLO, J.F. (2016): “Adaptación del sector turístico al cambio climático en España. La importancia de las acciones a escala local y en empresas turísticas". Anales de Geografía de la Universidad Complutense, vol. 36 (2), pp. 321 352 .

ORGANIZACIÓN DE NACIONES UNIDAS (1987): Informe Our Common Future: Brundtland Report. Report of the World Commission on Environment and Development. Organización de Naciones Unidas.

ORTEGA, E., RODRÍGUEZ, B. y SUCH, M.J. (2013): "Las tesis doctorales de turismo en España 2000-2012". Estudios Turísticos, n ${ }^{\circ}$ 195, pp. 9-31.

OTERO, A. (2007): "La importancia de la visión de territorio para la construcción de desarrollo competitivo de los destinos turísticos". Cuadernos de Turismo, nº 19, pp. 91-104.

OUTDOOR INDUSTRY ASSOCIATION (2017): The Outdoor Recreation Economy. Ed. Outdoor Industry Association (OIA), Colorado, USA.

PEÑA SÁNCHEZ, A. R., JIMÉNEZ GARCÍA, M., RUIZ CHICO, J. y PONTÓN ARICHA, T. (2019): "La producción científica en el "Sector de Hostelería y Turismo": Un análisis bibliométrico de las tesis doctorales españolas en el periodo 1978-2018". Investigaciones Turísticas, $\mathrm{n}^{\circ} 18$, pp. 71-94.

PLUMED, M., GÓMEZ BRUNA, D. y MARTÍN DUQUE, C. (2018): "Planificación turística, promoción y sostenibilidad ambiental: el caso de España”. Retos, vol. 8 (15), pp. 7-18.

PREVIDI, M., LIEPERT, B. G., PETEET, D., HANSEN, J., BEERLING, D. J., BROCCOLI, A. J., FROLKING, S., GALLOWAY, J. N., HEIMANN, M., LE QUERÉ, C., LEVITUSK, S., y RAMASWAMY, V. (2013): "Climate sensitivity in the Anthropocene". Quarterly Journal of the Royal Meteorological Society, vol. 139, pp. 1.1211.131 .

PULIDO-FERNÁNDEZ, J.I. (2004): "El medio ambiente en la política turística española". Quaderns de Política Econòmica, $\mathrm{n}^{\circ}$ 7, pp. 94-114.

PULIDO-FERNÁNDEZ, J.I., CÁRDENAS-GARCÍA, P.J. y ESPINOSA-PULIDO, J.A. (2019): Does environmental sustainability contribute to tourism growth? An analysis at the country level". Journal of Cleaner Production, vol. 213, pp. 309-319.

SAARINEN, J. (2006): "Traditions of sustainability in tourism studies". Annals of Tourism Research, vol. 33 (4), pp. 1.121-1.140.

SEPÚLVEDA, A. y PLUMED, M. (2018): "La investigación y la información estadística en turismo en España: hacia un sistema de conocimiento e inteligencia turística". Estudios Turísticos, $\mathrm{n}^{\circ}$ 215, pp. 101-120.

SERVICIO DE ESTUDIOS Y PLANIFICACIÓN DE LA AGÈNCIA VALENCIANA DEL TURISME (2006): "Análisis de las tesis doctorales de turismo realizadas en universidades españolas". Papers de Turisme, no 40, pp. 111-116. 
SHEPHARD, K. (2007): "Higher education for sustainability: Seeking affective learning outcomes". International Journal of Sustainability in Higher Education, vol. 9 (1), pp. 87-98.

TAYLOR, A. (2017): "Beyond stewardship: Common world pedagogies for the Anthropocene”. Environmental Education Research, vol. 23 (109), pp. 1.448-1.461.

TERUEL, L. y VIÑALS, M.J. (2020): "Teaching environmental sustainability and responsibility in the Anthropocene: Overview of Tourism Studies in Spain”. Journal of Teaching in Travel \& Tourism, vol. 20 (3), pp. 216-231.

TORRES DELGADO, A. (2013): “Turismo y sostenibilidad: una propuesta metodológica para el estudio de la sostenibilidad turística a escala municipal”. Investigaciones Turísticas, $\mathrm{n}^{\mathrm{O}}$ 5, pp. 163-171.

TORRES-ROJAS, A.A. y GARCÍA-DELGADO, F.J. (2015): "El Doctorado en Turismo en España: estado de la cuestión". EDUSK. Revista Monográfica de Educación Skepsis.org, $\mathrm{n}^{\circ}$ 5: pp. 1-49.

ULL, M.A., MARTÍNEZ AGUT, M., PIÑERO, A. y AZNAR, P. (2010): “Análisis de la introducción de la sostenibilidad en la enseñanza superior en Europa: compromisos institucionales y propuestas curriculares". Revista Eureka sobre Enseñanza y Divulgación de las Ciencias, n ${ }^{\circ}$ 7, pp. 413-432.

UNEP y UNWTO (2005): Making Tourism More Sustainable - A Guide for Policy Makers.

UNESCO (2016): Unpacking Sustainable Development: Goal 4 Education 2030. Ed. UNESCO. http://www.campaignforeducation.org/docs/post2015/SDG4.pdf

UNIÓN EUROPEA (2010). Declaración de Madrid por un turismo responsable. https:// decaba.com/wp-content/uploads/2010/05/declaracion-madrid-abril-2010-turismo-responsable.pdf

UNITED NATIONS (1999): Turismo y Desarrollo sostenible. https://documents-dds-ny. un.org/doc/UNDOC/GEN/N99/011/91/PDF/N9901191.pdf?OpenElement

UNITED NATIONS COMMISSION ON SUSTAINABLE DEVELOPMENT (1999): Tourism and sustainable development. UNCSD NGO Steering Committee, Background Paper \# 4. https://sustainabledevelopment.un.org/content/documents/401ngo4. pdf

WILSON, E. y VON DER HEIDT, T. (2013): "Business as usual? Barriers to education for sustainability in the tourism curriculum". Journal of Teaching in Travel \& Tourism, vol. 13 (2), pp. 130-147.

WORLD ECONOMIC FORUM (2019): The Travel \& Tourism Competitiveness. Report 2019. Ed. World Economic Forum, 42 pp. 


\section{ANEXO I. RECURSOS EN INTERNET}

Nota aclaratoria: los sitios webs consultados han sido actualizados en febrero de 2021. No obstante, cabe comentar que estos sitios web, por su naturaleza, muestran información dinámica susceptible de haber cambiado con respecto al momento en el que fueron analizados.

\section{Programas de máster:}

\begin{tabular}{|c|c|}
\hline Universidad A Coruña & https://estudos.udc.es/es/study/start/4524v01 \\
\hline $\begin{array}{l}\text { Universidad Antonio } \\
\text { Nebrija }\end{array}$ & https://www.nebrija.com/programas-postgrado/master/direccion-de-empresas-destinos-turisticos/ \\
\hline $\begin{array}{l}\text { Universidad Autónoma } \\
\text { de Barcelona }\end{array}$ & $\begin{array}{l}\text { https://www.uab.cat/web/estudiar/la-oferta-de-masteres-oficiales/informacion-general/gestion-de-empresas- } \\
\text { hoteleras-1096480309770.html?param1=1345664654609 }\end{array}$ \\
\hline $\begin{array}{l}\text { Universidad Autónoma } \\
\text { de Barcelona }\end{array}$ & $\begin{array}{l}\text { https://www.uab.cat/web/estudiar/la-oferta-de-masteres-oficiales/informacion-general/direccion-y- } \\
\text { organizacion-de-turismo-de-eventos-1096480309770.html?param1=1345648394879 }\end{array}$ \\
\hline $\begin{array}{l}\text { Universidad Autónoma } \\
\text { de Barcelona }\end{array}$ & $\begin{array}{l}\text { https://www.uab.cat/web/estudiar/la-oferta-de-masteres-oficiales/informacion-general/gestion-turistica-del- } \\
\text { patrimonio-cultural-1096480309770.html?param1=1345779544779 }\end{array}$ \\
\hline Universidad Barcelona & https://www.ub.edu/web/ub/es/estudis/oferta_formativa/master_universitari/fitxa/D/M0S0F/index.html \\
\hline $\begin{array}{l}\text { Universidad Carlos III de } \\
\text { Madrid }\end{array}$ & https://www.uc3m.es/master/gestion-turistica\#programa \\
\hline $\begin{array}{l}\text { Universidad Castilla La } \\
\text { Mancha }\end{array}$ & https://www.uclm.es/estudios/masteres/master-direccion-empresas-turisticas \\
\hline $\begin{array}{l}\text { Universidad Católica San } \\
\text { Antonio }\end{array}$ & https://online.ucam.edu/estudios/postgrados/direccion-hoteles-empresas-restauracion-a-distancia \\
\hline $\begin{array}{l}\text { Universidad Católica San } \\
\text { Antonio }\end{array}$ & $\begin{array}{l}\text { https://online.ucam.edu/estudios/postgrados/master-universitario-innovacion-y-marketing-turistico-a- } \\
\text { distancia }\end{array}$ \\
\hline $\begin{array}{l}\text { Universidad } \\
\text { Complutense Madrid }\end{array}$ & https://www.ucm.es/masterempresashoteleras \\
\hline $\begin{array}{l}\text { Universidad } \\
\text { Complutense Madrid }\end{array}$ & https://www.ucm.es/gestiondestinos \\
\hline Universidad de Alicante & https://web.ua.es/es/masteres-oficiales.html \\
\hline Universidad de Alicante & https://web.ua.es/es/masteres/turismo-cultural/ \\
\hline Universidad de Barcelona & $\begin{array}{l}\text { https://www.ostelea.com/programas/masters-universitarios-en-turismo/master-universitario-en-direccion- } \\
\text { hotelera }\end{array}$ \\
\hline Universidad de Barcelona & https://www.ub.edu/web/ub/es/estudis/oferta_formativa/master_universitari/fitxa/I/MDF01/index.html \\
\hline Universidad de Barcelona & https://www.ub.edu/web/ub/es/estudis/oferta_formativa/master_universitari/fitxa/T/M270B/index.html \\
\hline Universidad de Burgos & $\begin{array}{l}\text { https://www.ubu.es/master-universitario-en-cultura-del-vino-enoturismo-en-la-cuenca-del-duero- } \\
\text { semipresencial }\end{array}$ \\
\hline Universidad de Cádiz & https://ccsociales.uca.es/master/master-universitario-en-direccion-turistica/ \\
\hline Universidad de Cantabria & $\begin{array}{l}\text { https://web.unican.es/centros/economicas/masteres-oficiales/master-universitario-en-direccion-de- } \\
\text { marketing-empresas-turisticas }\end{array}$ \\
\hline Universidad de Cantabria & https://euturismoaltamira.com \\
\hline Universidad de Deusto & $\begin{array}{l}\text { https://www.deusto.es/cs/Satellite/deusto/es/masteres/estudios-masteres/direccion-de-proyectos-de-ocio- } \\
\text { cultura-turismo-deporte-y-recreacion/programa }\end{array}$ \\
\hline $\begin{array}{l}\text { Universidad de } \\
\text { Extremadura }\end{array}$ & $\begin{array}{l}\text { https://www.unex.es/organizacion/servicios-universitarios/servicios/servicio_becas/funciones/Masteres/ } \\
\text { masteres-oficiales-fichas/master-universitario-en-administracion-de-organizaciones-y-recursos-turisticos- } \\
\text { direccion-hotelera }\end{array}$ \\
\hline Universidad de Girona & https://www.udg.edu/es/masters-en-turisme/Direccio-i-planificacio \\
\hline Universidad de Girona & https://www.udg.edu/ca/masters-en-turisme/turisme-cultural \\
\hline Universidad de Girona & https://www.emtmmaster.net \\
\hline
\end{tabular}


Universidad de Huelva

Universidad de Jaén

Universidad de La

Laguna

Universidad de Las

Palmas de Gran Canaria

Universidad de les Illes

Balears

Universidad de Lleida

Universidad de Lleida

Universidad de Málaga

Universidad de Málaga

Universidad de Murcia

Universidad de Oviedo

Universidad de Santiago de Compostela

Universidad de Sevilla

Universitat de València

(Estudi General)

Universidad de Vigo

Universidad de Zaragoza

Universidad Distancia de Madrid

Universidad Europea de Canarias

Universidad Miguel

Hernández de Elche

Universitat Oberta de

Catalunya

Universidad Politécnica

de Cartagena

Universidad Politécnica de Madrid

Universidad Ramón Llull

Universidad Rey Juan

Carlos

Universidad Rey Juan

Carlos

Universidad Rey Juan

Carlos

Universidad Rovira i

Virgili

Universidad Rovira i

Virgili (Emundus)

Programa Conjunto:

Universidad de La

Laguna, Universidad de

Barcelona, Universidad

de Las Palmas de Gran

Canaria y Universidad

del Pais Vasco http://www.uhu.es/mastersoficiales/estudios/oferta-academica/master-oficial-en-turismo-direccion-deempresas-turisticas

https://www.ujaen.es/estudios/oferta-academica/masteres/master-universitario-en-planificacion-y-gestionsostenible-del-turismo

https://www.ull.es/masteres/direccion-planificacion-turismo/

http://www2.ulpgc.es/plan-estudio/5027

https://estudis.uib.es/es/estudis-de-master/master/METM/

https://www.ostelea.com/programas/masters-universitarios-en-turismo/master-universitario-en-gestionturistica-sostenible-de-recursos-y-destinos

https://www.ostelea.com/programas/masters-en-turismo/master-in-international-management-and-tourism

https://www.uma.es/master-en-turismo-electronico/

https://www.uma.es/master-en-direccion-y-planificacion-del-turismo/

https://www.um.es/web/turismo/contenido/estudios/masteres/gestion-hotelera

https://www.uniovi.es/estudios/masteres/masteres/-/asset_publisher/d0m7JOOPYmoL/content/masteruniversitario-en-direccion-y-planificacion-del-turismo;jsessionid=FB3F4C1A37D11C2E3BB7358D115671 8A?p_p_auth=spT1SO3d\&redirect=\%2Festudios $\% 2$ Fmasteres

https://www.usc.gal/es/centros/ecoade/titulacions.html?plan=14487\&estudio=17618\&codEstudio=16896\& valor $=9 \&$ orde $=$ true $\&$ ano $=70$

https://www.us.es/estudiar/que-estudiar/oferta-de-masteres/master-universitario-en-direccion-yplanificacion-del

https://www.uv.es/masterdeturismo

https://www.uvigo.gal/es/estudiar/que-estudiar/masters/master-universitario-direccion-planificacionturismo-interior-saude-o04m097v01

https://estudios.unizar.es/estudio/ver?id=633\&anyo_academico=2020

https://www.udima.es/es/master-direccion-empresas-hoteleras.html

https://universidadeuropea.com/master-direccion-hotelera-online/

https://www.umh.es/contenido/Estudios/:tit_m_203/datos_es.html

https://estudios.uoc.edu/es/masters-universitarios/turismo-sostenibilidad-tic/presentacion

https://www.upct.es/estudios/master/2082/

http://www.montes.upm.es/Estudiantes/EstudiosTitulaciones/Master_Oficiales/ MasterGestionTurismoEcologicoySostenible

https:/www.htsi.url.edu/masters/master-direccion-hotelera/

https://www.urjc.es/estudios/master\#ciencias-sociales-y-juridicas

https://www.urjc.es/estudios/master/900-direccion-internacional-del-turismo

https://www.urjc.es/estudios/master\#ciencias-sociales-y-juridicas

https://www.urv.cat/es/estudios/masteres/oferta/destinos-turisticos/

https://www.urv.cat/es/estudios/masteres/oferta/enoturismo/

https://www.ull.es/masteres/innovacion-en-diseno-para-el-sector-turistico/

Cuadernos de Turismo, 47, (2021), 487-513 


\section{Programas de doctorado:}

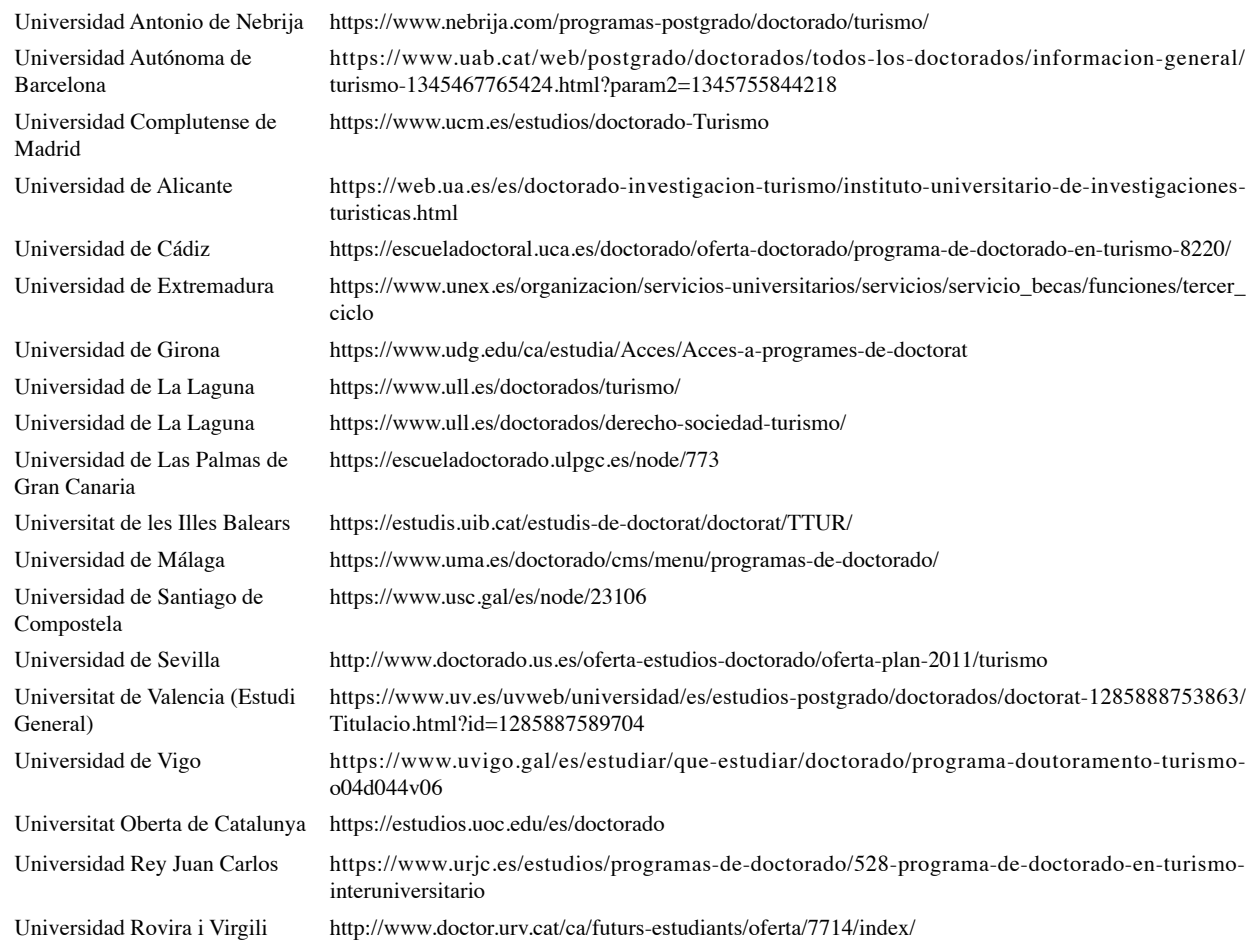

